\title{
Frequency, Clinical Presentation and Immediate Outcome of Hypernatraemic Dehydration in Children with Acute Diarrhoea
}

\author{
AZMERI SULTANA ${ }^{1}$, AFM SALIM $^{2}$, MOHAMMED HANIF $^{3}$, MFH NAZIR $^{2}$, RUMA PARVIN $^{1}$, \\ NAYEEMASADIA ${ }^{4}$, KHAN LAMIA NAHID ${ }^{5}$
}

\begin{abstract}
Background: Diarrhoea is a leading cause of illness \& death among children in developing countries. Hypernatraemia is a serious complication in acute diarrhoea. It is usually associated with high case fatality rate.

Objective: This study, was undertaken to measure the frequency of hypernatraemia, its clinical presentation and the immediate outcome of the problem in Specialized Paediatric Hospital settings.

Methods: This was cross sectional observational study. A total of hundred and seven children with acute diarrhoea aged between 2 months to 60 months of both sex admitted in the inpatient department of Dhaka Shishu Hospital and ICH and SSF Hospital, Mirpur-2, over a period of 6 months from August 2011 to February 2012 were included randomly in the study. Serum electrolytes was checked in all the study children just after admission before starting any treatment and at 24 and 72 hours after admission.

Results: Among 107 children, hypernatraemia accounted for 12(11.2\%) of children. Patients who developed hypernatraemia 4(33.3\%) were mild, 5(41.7\%) moderate and $3(25 \%)$ severely hypernatraemic. The proportion of children with consciousness at baseline and after 24 hours was staggeringly lower in severe hypernatraemic children than that in mild and moderate children. Intact sensory function was found in all mild \&severe hypernatraemic children at baseline. Twenty percent of moderate hypernatraemic children had paresthesia at baseline and another $20 \%$ after 72 hours, while 33.3\% of severe hypernatraemic patients exhibited after 24 hours. All of the patients had signs of severe dehydration at baseline in the three groups. Forty percent of moderate and $33.3 \%$ of severe hypernatraemic children had some signs of dehydration after 24 hours and $50 \%$ of mild, $40 \%$ of moderate and $66.7 \%$ of severe hypernatraemic patients after 72 hours. All of the mild and moderate and 1(33.3\%) in severe hypernatraemic children improve after treatment and 2(66.7\%) of 3 severe hypernatraemic children died during treatment.
\end{abstract}

Conclusion: Hypernatremia is a serious complication of acute diarrhoea in children, which is associated with increased mortality.

Keywords: Hypernatraemia, Acute Diarrhoea, Outcomes

1. Assistant professor, Department of Paediatric medicine, $\mathrm{ICH}$ \& SSF Hospital, Mirpur, Dhaka.

2. Professor of Paediatrics ICH \& SSF Hospital Mirpur-2, Dhaka

3. Professor of Paediatrics and head of the dept of PaedNephrology, Dhaka Shishu Hospital.

4. Assistant registrar, Uttara Adhunik Medical college And Hospital.

5. Junior Consultant, 500 bed Mugda General Hospital

Correspondence: Azmeri Sultana, Mobile: 01711311796,

E-mail: jhilni_me@yahoo.com
Introduction:

Acute diarrhea is defined as the abrupt onset of abnormally high fluid content in the stool: more than the normal value of approximately $10 \mathrm{~mL} / \mathrm{kg} / \mathrm{d}$ in the infant and young child. Dehydration as a result of diarrhoea continues to be a leading cause of death in children especially in developing countries. ${ }^{1}$ It is usually associated with high case fatality rate. ${ }^{2}$ 
Hypernatraemia (serum sodium concentration of 150 $\mathrm{mmol} / \mathrm{L}$ or more) is most likely to occur in a child suffering from diarrhoea with inadequate intake of fluid, repeated vomiting, intake of concentrated ORS or undiluted cow's milk. Most children with hypernatraemia are dehydrated, but do not show typical signs and symptoms of dehydration. ${ }^{3}$ Patients with hypernatraemia are usually irritable, restless, weak and lethargic. Alert patients are very thirsty, they may have fever. Seizure \& coma are possible squeals of brain hemorrhage. ${ }^{4}$ However, little is known about its magnitude and associated morbidity and mortality, particularly from developing countries. ${ }^{5}$ Two different studies from ICDDR,B showed the incidence of hypernatraemia to be $6.4 \%$ and $5.1 \%$, respectively. ${ }^{6}$ No such data is available from other Specialized Paediatric Hospitals in the country. WHO estimates that there are $>700$ million episodes of diarrhoea annually in children <5yrs of age in developing countries. While global mortality may be declining the overall incidence of diarrhoea remains unchanged at least 3.2 episodes/child/ year. The decline in diarrhoeal mortality, despite the lack of significant changes in incidence, is the result of improved case management of diarrhea, as well as improved nutrition of infants and children. These interventions have included widespread home and hospital based oral rehydration therapy, as well as improved nutritional management of children with diarrhoea .Persistently high rates of diarrhoea among young children despite intensive efforts at control are of particular concern. ${ }^{7}$ The objective of the study is to find out the frequency of hypernatraemia, its clinical presentation and the immediate outcome in two different specialist paediatric hospital settings.

\section{Methodology:}

This prospective comparative study was conducted in inpatient departments of Dhaka Shishu Hospital, Sher-e-Bangla Nagar, Shyamoli and ICH \& Shishu Sasthya Foundation Hospital, Mirpur-2, Dhaka over a period of 6 months from $10^{\text {th }}$ August,2011to10th February 2012. Total 107 children aged 2 months to 5 years admitted for acute watery diarrhoea were selected consecutively for the study. Written consents were obtained from the accompanying persons. They were then assessed for clinical conditions following the inpatient pediatric protocol at the selected hospital. Structured questionnaire including clinical and laboratory data were completed for all cases. Blood samples were collected just after clinical examination and the treatment was started according to standard protocol of the hospital. All the patients were then followed up for 72 hours to see the treatment outcome. Investigation results were obtained within 4 hours of admission and once there was hypernatraemia, the serum electrolytes were repeated at 24 and 72 hours. The outcomes were cautiously recorded and later analyzed. For data analysis, SPSS statistical package was used and analyzed using Chi-square $\left(\chi^{2}\right)$ Test, One-Way ANOVA Test and Repeated MeasureANOVA statistics. Children who had persistent diarrhoea, acute diarrhoea with associated problems, blood mixed stool, parents of children unwilling to give consent were excluded from the study.

\section{Results:}

A total of 107 patients age ranging from 2 months to 5 years were enrolled for the study, of which 12(11.2\%) were found hypernatraemic. Among them, 4 patients had mild $\left(\mathrm{Na}^{+}:<160 \mathrm{mmol} / \mathrm{L}\right) ; 5$ had moderate $\left(\mathrm{Na}^{+}\right.$ $: 160-170 \mathrm{mmol} / \mathrm{L})$ and $3 \mathrm{had}$ severe $\left(\mathrm{Na}^{+}:>170 \mathrm{mmol} /\right.$

Table I

Demographic characteristics among the three groups

\begin{tabular}{|c|c|c|c|c|}
\hline \multirow[b]{2}{*}{$\begin{array}{l}\text { Demographic } \\
\text { characteristics }\end{array}$} & \multicolumn{3}{|c|}{ Hypernatraemia } & \multirow[t]{2}{*}{$p$-value } \\
\hline & $\begin{array}{c}\text { Mild } \\
(n=4)\end{array}$ & $\begin{array}{c}\text { Moderate } \\
(\mathrm{n}=5)\end{array}$ & $\begin{array}{l}\text { Severe } \\
(n=3)\end{array}$ & \\
\hline \multicolumn{5}{|l|}{$\overline{\text { Age (months) }}$} \\
\hline $2-23$ & 4(100.0) & $4(80.0)$ & $1(33.3)$ & \\
\hline $24-60$ & 00 & $1(20.0)$ & $2(66.7)$ & \\
\hline Mean \pm SD & $3.4 \pm 1.5$ & $1.0 \pm 0.6$ & $0.6 \pm 0.3$ & 0.114 \\
\hline \multicolumn{5}{|l|}{$\mathrm{Sex}^{*}$} \\
\hline Male & $2(50.0)$ & $3(60.0)$ & $1(33.3)$ & 0.766 \\
\hline Female & $2(50.0)$ & $2(40.0)$ & $2(66.7)$ & \\
\hline Weight $^{\#}$ & $5.2 \pm 0.7$ & $6.5 \pm 1.8$ & $15.3 \pm 4.6$ & 0.046 \\
\hline
\end{tabular}

\# ANOVA statistics was used to analyses the data and presented as mean $\pm \mathbf{S D}$; ${ }^{*}$ Data were analyzed using Chi-square $\left(\chi^{2}\right)$ Test. 
L) hypernatraemia. All 4 children with mild and 4 out of 5 with moderate and 1out of 3 severe hypernatraemic children were between 2 months to 23 months, while 2 out of $3(66.7 \%)$ of severe and 1out of $5(20 \%)$ moderate hypernatraemic children were between 24-60 months. Eight out of 12 children with mild, moderate and severe hypernatraemia were suffering for diarrhoea for 3 days, while 2 out of $3(66.7 \%)$ with severe, and 1out of 5 with moderate(20\%) suffered for 4 days. Vomiting was present in all 3 groups but vomiting for $\geq 3$ days was present in $20 \%$ moderate and $100 \%$ severe hypernatraemic group. Other signs and symptoms like convulsion, irritability, seizures, increased muscle tone and oliguria were higher in severe hypernatraemic patients than mild and moderate patients ( $0 \%$ vs. $40 \%$ vs. $100 \%, p=0.029$; $75 \%$ vs. $80 \%$ vs. $100 \%, p=0.657 ; 50 \%$ vs. $60 \%$ vs. $66.7 \%, p=0.902 ; 25 \%$ vs. $60 \%$ vs. $100 \%, p=0.137$ respectively) (Table II).

Table II

Sign \& symptoms among the three groups

\begin{tabular}{|c|c|c|c|c|}
\hline \multirow[t]{2}{*}{ Sign \& symptoms } & \multicolumn{3}{|c|}{ Hypernatraemia } & \multirow{2}{*}{$\begin{array}{c}\mathrm{p}- \\
\text { value }\end{array}$} \\
\hline & $\begin{array}{c}\text { Mild } \\
(n=4)\end{array}$ & $\begin{array}{l}\text { Moderate } \\
(\mathrm{n}=5)\end{array}$ & $\begin{array}{l}\text { Severe } \\
(n=3)\end{array}$ & \\
\hline \multicolumn{5}{|l|}{ Duration of diarrhea } \\
\hline 2 days & 00 & $1(20.0)$ & 00 & \\
\hline 3 days & $4(100.0)$ & $3(60.0)$ & 1(33.3) & 0.220 \\
\hline 4 days & 00 & $1(20.0)$ & $2(66.7)$ & \\
\hline Vomiting & $3(75.0)$ & $5(100.0)$ & $3(100.0)$ & 0.336 \\
\hline \multicolumn{5}{|l|}{ Duration of vomiting } \\
\hline 1 day & $2(66.7)$ & $1(20.0)$ & 00 & \\
\hline 2 days & 1(33.3) & $3(60.0)$ & 00 & 0.359 \\
\hline$\geq 3$ days & 00 & $1(20.0)$ & $3(100.0)$ & \\
\hline Convulsion & 00 & $2(40.0)$ & $3(100.0)$ & 0.029 \\
\hline Irritability & $3(75.0)$ & $4(80.0)$ & $3(100.0)$ & 0.657 \\
\hline High-pitched cry & $1(25.0)$ & $5(100.0)$ & 00 & 0.011 \\
\hline Seizures & 00 & $2(40.0)$ & $3(100.0)$ & 0.029 \\
\hline $\begin{array}{l}\text { Increased muscle } \\
\text { tone }\end{array}$ & $2(50.0)$ & $3(60.0)$ & $2(66.7)$ & 0.902 \\
\hline Oliguria & $1(25.0)$ & $3(60.0)$ & $3(100.0)$ & 0.137 \\
\hline
\end{tabular}

* Data were analyzed using Chi-square $\left(\chi^{2}\right)$ Test.

The proportion of patients with intact consciousness at baseline and after 24 hours was lower in the severe hypernatraemic patients than that in the mild and moderate groups. However, the percentage of intact consciousness after 72 hours was less in moderate hypernatraemic patients compared to other counterparts. Fifty percent (50\%) of patients in mild and $60 \%$ moderate hypernatraemic patients had normal motor function, while all severe hypernatraemic patients had abnormal motor functions. The improvement of motor function reached to $100 \%$ in mild and moderate hypernatraemic patients within 3 days of treatment, but not in the severe group. In all of them motor functions took more than 3 days to return to normal. Intact sensory function was available in mild, moderate and severe hypernatraemic patients at baseline. Twenty percent of moderate hypernatraemic patients had paresthesia at baseline and it continued up to 72 hours, while $33.3 \%$ of severe hypernatraemic patients developed paresthesia after 24 hours and returned to normal at 72 hours. All of the patients had signs of severe dehydration at baseline in all three groups. After 24 hours, $40 \%$ of moderate and $33.3 \%$ of severe hypernatraemic patients still had some signs of dehydration $(p=0.360)$ (Table III).

\section{Table III}

Monitoring of clinical examination throughout observation period

\begin{tabular}{|c|c|c|c|c|}
\hline \multirow{2}{*}{ Clinical examination } & \multicolumn{3}{|c|}{ Hypernatraemia } & p- \\
\hline & $\begin{array}{c}\text { Mild } \\
(n=4)\end{array}$ & $\begin{array}{c}\text { Moderate } \\
(n=5)\end{array}$ & $\begin{array}{c}\text { Severe } \\
(n=3)\end{array}$ & value \\
\hline
\end{tabular}

Intact Consciousness*

\begin{tabular}{|c|c|c|c|c|}
\hline At baseline & $4(100.0)$ & $5(100.0)$ & 1(33.3) & 0.027 \\
\hline After 24 hours & $4(100.0)$ & $5(100.0)$ & $2(66.7)$ & 0.195 \\
\hline After 72 hours & $4(100.0)$ & $4(80.0)$ & $3(100.0)$ & 0.466 \\
\hline \multicolumn{5}{|c|}{ Motor function (Normal)* } \\
\hline At baseline & $2(50.0)$ & $3(60.0)$ & 00 & 0.016 \\
\hline fter 24 hours & $4(100.0)$ & $4(80.0)$ & 1(33.3) & 0.195 \\
\hline After 72 hours & $4(100.0)$ & $5(100.0)$ & 1(33.3) & .466 \\
\hline \multicolumn{5}{|c|}{ Sensory function\# at baseline } \\
\hline Intact & $4(100.0)$ & $4(80.0)$ & $3(100.0)$ & 0.466 \\
\hline Parasthesia & 00 & $1(20.0)$ & 00 & \\
\hline \multicolumn{5}{|l|}{ After 24 hours } \\
\hline Intact & $4(100.0)$ & $5(100.0)$ & $2(66.7)$ & 0.195 \\
\hline arasthesia & 00 & 00 & 1(33.3) & \\
\hline \multicolumn{5}{|l|}{ After 72 hours } \\
\hline Intact & $4(100.0)$ & $4(80.0)$ & $3(100.0)$ & 0.466 \\
\hline Parasthesia & 00 & $1(20.0)$ & 00 & \\
\hline \multicolumn{5}{|c|}{ Dehydration status* } \\
\hline \multicolumn{5}{|l|}{ At baseline } \\
\hline Severe sign & $4(100.0)$ & $5(100.0)$ & $3(100.0)$ & - \\
\hline \multicolumn{5}{|l|}{ After 24 hours } \\
\hline No sign & $4(100.0)$ & $3(60.0)$ & $2(66.7)$ & 0.360 \\
\hline Some sign & 00 & $2(40.0)$ & 1(33.3) & \\
\hline \multicolumn{5}{|l|}{ After 72 hours } \\
\hline No sign & $2(50.0)$ & $3(60.0)$ & 1(33.3) & 0.766 \\
\hline Some sign & $2(50.0)$ & $2(40.0)$ & $2(66.7)$ & \\
\hline
\end{tabular}

\# Repeated measure ANOVA statistics was employed to analyse the data and ' $p$ ' refers to overall differences between groups * Data were analyzed using Chi-square $\left(\chi^{2}\right)$ Test. 
Three (75\%) mild hypernatraemic, 3 (60\%) moderate and 1 (33.3\%) severe hypernatraemic patients received oral rehydration solutions (ORS). Two (50\%) mild, 4 (60\%) moderate and 1 (33.3\%) hypernatraemic patient had a history of medication before hospitalization. Every one of the hypernatraemic patients was given IV fluid immediately to replace fluid deficit. Two (40\%) out of 5 moderate and $3(100 \%)$ of severe hypernatraemic patients needed dialysis for acute disease $(p=0.029)$ (Table IV). All of the mild and moderate and $1(33.3 \%)$ severe hypernatraemic patients improved, while $2(66.7 \%)$ of 3 severe hypernatraemic patients died during treatment (Figure 1).

Table-IV

Treatment history throughout observation period

\begin{tabular}{|c|c|c|c|c|}
\hline \multirow[t]{2}{*}{ Treatment history } & \multicolumn{3}{|c|}{ Hypernatraemia } & \multirow{2}{*}{$\begin{array}{c}\mathrm{p}- \\
\text { value }\end{array}$} \\
\hline & $\begin{array}{c}\text { Mild } \\
(n=4)\end{array}$ & $\begin{array}{l}\text { Moderate } \\
(\mathrm{n}=5)\end{array}$ & $\begin{array}{l}\text { Severe } \\
(n=3)\end{array}$ & \\
\hline Given ORS & $3(75.0)$ & $3(60.0)$ & 1(33.3) & 0.539 \\
\hline $\begin{array}{l}\text { Medication before } \\
\text { hospitalization }\end{array}$ & $2(50.0)$ & $4(60.0)$ & 1(33.3) & 0.396 \\
\hline $\begin{array}{l}\text { Intravenous fluid } \\
\text { administration }\end{array}$ & $4(100.0)$ & $5(100.0)$ & $3(100.0)$ & - \\
\hline Dialysis & 00 & $2(40.0)$ & $3(100.0)$ & 0.029 \\
\hline
\end{tabular}

* Data were analyzed using Chi-square $\left(\mathbf{c}^{2}\right)$ Test

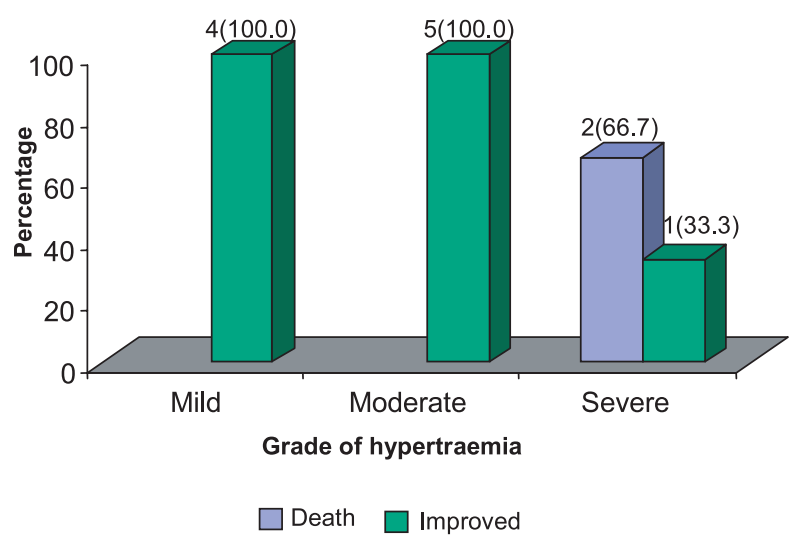

Fig.-1: Comparison of outcome among grade of hypernatraemia

\section{Discussion:}

The present study highlights the prevalence of hypertrenaemia (serum $\mathrm{Na}^{+} \geq 150 \mathrm{mEq} / \mathrm{L}$ ) in hospitalized patient, which was approximately $11.2 \%$. Anderson et all ${ }^{8-9}$ found a prevalence of $10.4 \%$ when defining hypertrenaemia as serum sodium concentration $\geq 150 \mathrm{mEq} / \mathrm{L}$; our results using this definition is similar. Findings of current study showed mean age and weight of severe hypernatraemic patients was higher than those of mild and moderate and male was higher in moderate compared to those in mild and severe hypernatremic patients. All (100\%) of mild hypernatraemic patients were suffering from acute diarrhea for three days. In case of moderate hypernatraemia, $20 \%$ patients were suffering from diarrhoea for two days, $60 \%$ for three days and another $20 \%$ for four days. One-third $(33.3 \%)$ of severe hypernatraemic patients were suffering from diarrhoea for three days and rest $66.7 \%$ for four days. Three (75\%) mild hypernatraemic patients exhibited vomiting (66.7\% for one day and $33.3 \%$ for two days). All (100\%) moderate hypernatraemic patients had vomiting (20\% for one day, $60 \%$ for two days and $20 \% \geq$ three days) and all (100\%) severe hypernatraemic patients had vomiting for $\geq 3$ days.

The patients with other signs and symptoms like convulsion, irritability, seizures, increased in muscle tone were higher in severe hypernatraemic patients than mild and moderate patients. As has been stressed in these studies, Tierney et al ${ }^{10}$ reported that $11(10.7 \%)$ of 103 patients developed hypernatraemia during hospitalization. Patients who developed hypernatraemia during hospitalization were younger in case of mild hypernatraemia than moderate and severe patients (mean age \pm SD, $1.9 \pm 0.2$ years compared with $2.6 \pm 1.7$ years and $3.7 \pm 0.9$ years; $P$ $<0.01$ ). Fifty-five percent of severe hypernatraemic patients had increased insensible water losses and $35 \%$ had convulsion, $76 \%$ high-pitched cry or wail. However, previous study conducted by Long et al ${ }^{11}$ observed that vomiting and increased muscle tone varied widely among different grade of hypernatremic patients.

Consciousness at baseline was intact in all patients in mild and moderate hypernatraemic pt, but significantly worse in patients with severe hypernatraemia(66\%) than with moderate and mild hypernatraemia. At 72 hours, consciousness improved in all patients. Surprisingly, however, it was still somehow altered in patients with moderate hypernatraemia, although it returned to almost normal in patients with mild and severe hypernatraemia. The reason for this discrepancy remained unclear. 
Abnormal motor function (hypo or hypertonic) was observed in all the patients with severe hypernatraemia, while the same was observed in 50\% in mild and 40\% in moderate hypernatraemic patients. Twenty percent of moderate hypernatraemic patients had complaint of paresthesia at baseline, and another $20 \%$ developed the same at 72 hours, while only $33.3 \%$ of severe hypernatraemic patients exhibited the same at 24 hours. On the other hand, none of the patients with mild hypernatraemia had any complaint of altered sensory function. Almost similar results of paresthesia was also reported by others. ${ }^{12}$ Snyder \& Merson, however, found that some residual weakness was still persisting in some patients even after 72 hours who had both motor and sensory function altered. They, therefore, emphasized that long time follow up would be essential in these patients. ${ }^{13}$

Our study reveals that all the patients with mild and moderate and 1 (33.3\%) of severe hypernatraemic patients improved after treatment. Two $(66.7 \%)$ of 3 severe hypernatraemic children died during treatment. Alshayeb and associates ${ }^{14}$ demonstrated that mean admission serum $\mathrm{Na}^{+}$level was $159 \pm 3 \mathrm{mEq} / \mathrm{L}$. Ninety percent of their patients received the recommended $<0.5 \mathrm{mEq} / \mathrm{L} / \mathrm{hr}$ serum $\mathrm{Na}^{+}$correction rate; however, hypernatremia was corrected only in $27 \%$ of patients after 72 hours of treatment. On third-day, patient mortality rate was $37 \%$. The mortality rate in our study $(66.7 \%)$ in severe hypernatraemia was almost similar with other studies (66\%). ${ }^{15-16}$ The mortality we also observed is similar to that reported in other studies of hypernatremia. $7,15,17,18,19,20$

\section{Conclusion:}

Hypernatraemia is not uncommon in our hospitalized population. There are important differences in the prognostic significance of hypernatraemia across clinical settings. Hypernatraemic dehydration remains an important, serious complication in this study and resulted high mortality in patients with severe hypernatraemia. Early identification, proper medical examination and management may be helpful for the solution of the problem and can provide the exact estimate of the burden.

\section{References}

1. Puffer RR, Serrano CV. Pattern of mortality in childhood: report of inter-American investigation of mortality in childhood. Washington, DC. Pan American Health Organisation, 1973; scientific publication No262.
2. George L, Vasilis T, Michalis D, Athanasia S, Eleni B \& Moses E. Clinical and laboratory characteristics of hypernatraemia in an internal medicine clinic. Oxford Journal. 2007;2: 136-43.

3. Behrman RE, Kliegman RM, Jenson HB, Stanton BF. Nelson textbook of Paediatrics: Acute Gastroenteritis In children. $18^{\text {th }}$ ed. Vol 2. Philadelphia: W.B Saunders company; 2007. p. 1605

4. Behrman RE, Kliegman RM, Jenson HB, Stanton BF. Nelson textbook of Paediatrics: Electrolyte and acid base disorder. 18 $8^{\text {th }}$ ed. Vol 1. Philadelphia: W.B Saunders company; 2007. p. 273.

5. Ahmed S, Chisti MJ, Ahmed T. Hypernatraemia as a complication of diarrhoea \& presenting features and outcome of the treatment. Proceeding of $10^{\text {th }}$ Asian Conference On Diarrhoeal Diseases and Nutrition: 2003 Dec 79; p. 66.

6. Samadi AR, Wahed MA, Islam MR, Ahmed SM. Consequences of hyponatraemia and hypernatraemia in children with acute diarrhoea in Bangladesh. British Medical Journal 1983; 286: 671-3

7. Ahmed S, Chisti MJ, Ahmed T. Hypernatraemia as a complication of diarrhoea \& presenting features and outcome of the treatment. Proceeding of $10^{\text {th }}$ Asian Conference On Diarrhoeal Diseases and Nutrition: 2003 Dec 79; p. 67.

8. Ahmed S, Chisti MJ, Ahmed T. Hypernatraemia as a complication of diarrhoea \& presenting features and outcome of the treatment. Proceeding of $10^{\text {th }}$ Asian Conference On Diarrhoeal Diseases and Nutrition: 2003 Dec 79; p. 68.

9. Anderson RJ, Chung HM, Kluge R, Schrier RW. Hyponatremia: a prospective analysis of its epidemiology and the pathogenetic role of vasopressin. Ann Intern Med 1985;102:164-8.

10. Tierney WM, Martin DK, Greenlee MC, Zerbe $\mathrm{RL}, \mathrm{McDonald} \mathrm{CJ}$. The prognosis of hyponatremia at hospital admission. J Gen Intern Med. 1986;1:380-5. 
11. Long CA, Marin P, Bayer AG, Shetty HG, Pathy MS. Hypernatraemia in an adult in-patient population. Postgraduate Medical Journal 1991; 67: 643-5.

12. Snyder JD, Merson MH. The magnitude of the global problem of acute diarrhoeal disease: a review of active surveillance data. Bull World Health Organ 1982;60:605-13

13. Barr SI, Costill DL, Fink WJ. Fluid replacement during prolonged exercise: effects of water, saline, or no fluid. Med Sci Sports Exerc 1991; 23: 811-17.

14. Alshayeb H, Showkat A, Babar F, Mangold T, Wall B. Severe Hypernatremia Correction Rate and Mortality in Hospitalized Patients. American Journal of the Medical Sciences 2011; 341: 356-60.

15. McConnel GK, Burge CM, Skinner SL, Hargreaves M. Influence of ingested fluid volume on physiological responses during prolonged exercise. Acta Physiol. Scand 1997;160:149-56.
16. Irving RA, Noakes TD, Buck R, van Zyl Smit R, Raine E, Godlonton J. Evaluation of renal function \&fluid homeostasis during recovery from exercise induced hyponatraemia. Journal of Applied Physiology 1999;70:342-48.

17. Dutta D, Bhattacharya MK, Deb AK. Evaluation of oral hypo-osmolar glucose based and ricebased oral rehydration solutions in the treatment of cholera in children. Acta Paediatr 2000;89: 787-90.

18. Bern C, Martines J, de Zoysa I, Glass RI. The magnitude of the global problem of diarrhoeal disease: a ten-year update. Bull World Health Organ 1992;70:705-14.

19. Guandalini S. Probiotics for children with diarrhea: an update. Journal of Clinical Gastroenterology 2008; 42: S53-7.

20. Field M. Intestinal ion transport and the pathophysiology of diarrhea. Jounal of Clinical pathology 2003;111:931-43. 